\title{
Predicted Indirectly ReCognizable HLA Epitopes (PIRCHE) Are Associated with Poorer Outcome after Single Mismatch Unrelated Donor Stem Cell Transplantation: A Study of the Cooperative Transplant Study Group (KTS) of the German Group for Bone Marrow and Stem Cell Transplantation (DAG-KBT)
}

\author{
Francis Ayuk $^{a}$ Martin Bornhäuser ${ }^{b}$ Matthias Stelljes ${ }^{c}$ Tatjana Zabelina $^{a}$ Eva-Maria Wagner ${ }^{d}$ \\ Christoph Schmid $^{\mathrm{e}}$ Maximilian Christopeit ${ }^{\mathrm{a}}$ Martina Guellstorf ${ }^{\mathrm{a}}$ Nicolaus Kröger $^{\mathrm{a}}$ \\ Wolfgang Bethge ${ }^{f}$ \\ ${ }^{a}$ Department of Stem Cell Transplantation, University Medical Center Hamburg-Eppendorf, Hamburg, Germany; \\ ${ }^{b}$ Medizinische Klinik und Poliklinik I, Universitätsklinikum Carl Gustav Carus der TU Dresden, Dresden, Germany; \\ 'Department of Medicine/Hematology and Oncology, University of Münster, Münster, Germany; ${ }^{\mathrm{d}}$ Department of

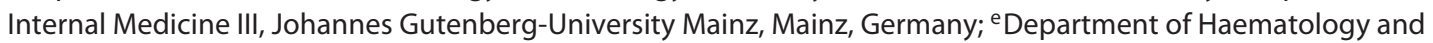 \\ Oncology, Klinikum Augsburg, University of Augsburg, Augsburg, Germany; ${ }^{f}$ Hematology and Oncology, Medical \\ Center, University of Tübingen, Tübingen, Germany
}

\section{Keywords}

PIRCHE · Outcome · Allogeneic hematopoietic stem cell transplantation

\section{Abstract}

There is no established standard for selection of mismatched unrelated donors. Indirect recognition of HLA mismatches can be predicted using the model of "Predicted Indirectly ReCognizable HLA Epitopes" (PIRCHE). We performed a multicenter retrospective study evaluating the impact PIRCHE on outcome after allogeneic stem cell transplantation (alloHSCT) from single mismatched (HLA 9/10 matched) unrelated donors. The study cohort included 424 adult recipients of HLA 9/10 matched unrelated donor transplants (9/10 MUD), treated for AML or MDS at 6 transplant centers across Germany. Detection of PIRCHE was associated with lower overall survival (OS) (47 vs. 57\%, $p=0.04$ ), higher non-relapse mortality (NRM) (32 vs. 20\%, $p=0.05$ ), and higher incidence of chronic graft-versus-host disease (GVHD) (49 vs. $31 \%, p=$
0.04 ) at 2 years. Cumulative incidence of acute GVHD grade $2-4$ at 6 months was not significantly different (30 vs. $23 \%$, $p=0.2$ ). OS for $9 / 10$ MUD with no PIRCHE was similar to $10 / 10$ MUD (57 vs. 55\%). In multivariate analysis, PIRCHE retained negative impact on OS (RR 1.5,95\% Cl 1.0-2.1, $p=0.03$ ) and NRM (RR 1.7, 95\% Cl 1.0-2.9, $p=0.03$ ). To the best of our knowledge, for the first time, we show the association of PIRCHE and survival outcome after allo-HSCT. The PIRCHE model, if validated in an independent cohort, may allow selection of permissible HLA mismatches that enable improved transplant outcome.

(c) 2019 S. Karger AG, Basel

\section{Introduction}

Allogeneic hematopoietic stem cell transplantation (HSCT) is a curative therapy for several hematological disorders. If no matched related donor is available, the probability of finding a fully HLA-matched unrelated

\section{KARGER}

(C) 2019 S. Karger AG, Basel 
donor (MUD) may be as low as 16\%, depending on the patient's ethnical background [1]. Donor-recipient HLA mismatching is associated with poorer outcome [2-6]. Transplant outcome with permissible HLA mismatches such as in HLA-DPB1 or HLA-C*03:03/03:04 is similar to that with fully matched unrelated donors [7-11].

Direct recognition of HLA-DPB1 mismatches can be predicted using the TCE (T-cell epitope) model, based on which DPB1 mismatches can be categorized as permissive or non-permissive $[9,10]$. Direct recognition of HLA mismatches can also be predicted by in silico models; however, none of them has so far predicted clinical outcome $[12,13]$. Indirect recognition of HLA mismatches can be predicted using the model of "Predicted Indirectly ReCognizable HLA Epitopes" (PIRCHE). The PIRCHE model is a recently developed computer-based strategy, which classifies HLA-derived epitopes that are potentially presented by patient-donor shared HLA molecules. Accordingly, PIRCHE-I are presented by shared HLA class I and PIRCHE-II by shared HLA class II molecules, independent of the mismatched locus [14]. PIRCHE numbers correlate with incidence of acute graft-versushost disease (GVHD) [15].

We reasoned that by predicting donor-recipient alloreactivity, the PIRCHE model separates permissible from non-permissible HLA mismatches and would therefore predict outcome after single-mismatched (9/10 MUD) HSCT.

\section{Patients and Methods}

A study protocol was written by F.A. and W.B. and amended by the German cooperative transplant study group. Data were collected according to EBMT guidelines and updated as of January 2016. Written informed consent was available from all patients.

The main objective was evaluation of the impact of PIRCHE on outcome of 9/10 MUD HSCT. The primary endpoint was overall survival (OS) at 2 years. Secondary endpoints were cumulative incidence of acute GVHD at 6 months, non-relapse mortality (NRM) at 2 years, and chronic GVHD at 2 years.

Unambiguous allele-level high-resolution HLA-A, -B, -C, -DRB1, and -DQB1 typing was available for all patient-unrelated donor pairs at the time of transplant. Lower level typing was considered sufficient for related donors. Transplants from mismatched related donors and those using umbilical cord blood grafts were excluded from the analysis.

The entire study included 1,997 adult patients: matched related donors $=481,10 / 10 \mathrm{MUD}=978,9 / 10 \mathrm{MUD}=424,8 / 10 \mathrm{MUD}=$ $97,7 / 10 \mathrm{MUD}=17$. Detailed analyses were performed in the cohort of patients with a $9 / 10$ MUD $(n=424)$.

PIRCHE numbers were computed for 9/10 MUD using a webbased tool provided by PIRCHE AG (www.pirche.org). Accordingly, PIRCHE I and II values were computed for each patient and the sum of PIRCHE I and II was considered as PIRCHE score. Patients with a 9/10 MUD were then divided into 2 groups according to the sum of PIRCHE I + II values (PIRCHE score). Eighty-five patients had a PIRCHE score of 0 (no PIRCHE detected), 339 a PIRCHE score $>0$.

PIRCHE Score Predicts Survival after Allogeneic Transplant
Patient characteristics of the 424 patients with 9/10 MUD are summarized in Table 1. Acute and chronic GVHD were defined according to international consensus criteria $[16,17]$. Details of HLA mismatches and their respective PIRCHE numbers are provided as online supplementary Table S1 (for all online suppl. material, see www.karger.com/doi/10.1159/000502389).

\section{Statistical Analysis}

Categorical variables were expressed as frequencies, while continuous variables were expressed as medians and ranges. For all analyses, patients still alive were censored at last follow-up. If patients received a second allogeneic transplant, they were considered alive or dead due to relapse or NRM if the event occurred. Missing data were excluded from analysis.

Categorical data were compared by chi-square test or Fisher's exact test. OS was estimated using the method of Kaplan-Meier and compared using the log-rank test. Competing risk analyses were performed with death as competing risk for acute GVHD and chronic GVHD and relapse as competing risk for NRM.

All parameters in patient demographics (Table 1) were included in the univariate analysis. Parameters with $p<0.05$ were thereafter entered into a Cox regression model with stepwise backward elimination (Wald). All reported $p$ values are two-sided. Though not significant in univariate analysis, HLA-C allele vs. antigen mismatch and HLA-C*03:03 vs. 03:04 mismatch were also included in multivariate analysis models because they were not evenly distributed (Table 1).

Calculations were performed with IBM SPSS, version 22 (SPSS Inc., Chicago, IL, USA). Competing risks analyses were performed using R (www.r-project.org).

\section{Results}

\section{Overall Survival}

First, we examined the impact of the PIRCHE score (sum of PIRCHE I and II) on OS of the patient cohort. Kaplan-Meier estimate of 2-year OS was higher for 9/10 MUD with a PIRCHE score $=0$ compared to $>0: 57 \%$ (95\% CI $51-63 \%)$ vs. $47 \%$ (95\% CI $41-53 \%), p=0.04$ (Fig. 1). OS was similar for $9 / 10$ MUD with a PIRCHE score $=0$ and 10/10 MUD (57 vs. 55\%). Neither PIRCHE I nor PIRCHE II alone had significant impact on OS (data not shown). Cox regression analysis revealed poorer OS for PIRCHE score $>0$ (RR 1.5, 95\% CI 1.0-2.1, $p=0.03$; Table 2a).

\section{Relapse and Non-Relapse Mortality}

Next, we sought to understand the reason for the difference in OS and therefore analyzed the impact of PIRCHE score on NRM and relapse. Cumulative incidence of NRM at 2 years was lower for 9/10 MUD with PIRCHE score $=0$ compared to a PIRCHE score $>0$ (20 vs. $32 \%, p=0.05$; Fig. 2). Multivariate Cox regression analysis revealed poorer NRM for PIRCHE score $>0$ (RR $1.7,95 \%$ CI 1.0-2.9, $p=0.03$; Table 2b). Cumulative incidence of relapse was similar for 9/10 MUD with PIRCHE score $=0$ compared to a PIRCHE score $>0$ (22 vs. $23 \%$, $p=0.73)$. 
Table 1. Characteristics of patients with 9/10 HLA-matched unrelated donors $(n=424)$

\begin{tabular}{|c|c|c|c|}
\hline Characteristics & PIRCHE $=0$ & PIRCHE $>0$ & $p$ value \\
\hline Patient sex $(n=424)$ & & & 0.7 \\
\hline Female & $39(46)$ & $143(42)$ & \\
\hline Male & $46(54)$ & $196(58)$ & \\
\hline Donor sex $(n=411)$ & & & 1.0 \\
\hline Female & $27(32)$ & $108(33)$ & \\
\hline Male & $56(68)$ & $220(67)$ & \\
\hline Patient/donor gender constellation $(n=411)$ & & & 1.0 \\
\hline Male/female & $11(13)$ & $43(13)$ & \\
\hline Other & $72(87)$ & $285(87)$ & \\
\hline Patient age in years $(n=424)$ & $57(19-76)$ & $58(19-77)$ & 0.6 \\
\hline Donor age in years $(n=324)$ & $35(19-52)$ & $35(18-59)$ & 0.5 \\
\hline Patient CMV status $(n=422)$ & & & 0.2 \\
\hline Positive & $55(66)$ & $196(58)$ & \\
\hline Negative & $29(34)$ & $142(42)$ & \\
\hline Donor CMV status $(n=422)$ & & & 1.0 \\
\hline Positive & $38(45)$ & $152(45)$ & \\
\hline Negative & $46(55)$ & $186(55)$ & \\
\hline Patient/donor CMV constellation donor $(n=422)$ & & & 0.2 \\
\hline Positive/negative & $26(31)$ & $81(24)$ & \\
\hline Other & $58(69)$ & $257(76)$ & \\
\hline Transplant year $(n=424)$ & & & 0.39 \\
\hline $2005-2009$ & $38(45)$ & $133(39)$ & \\
\hline 2010-2014 & $47(55)$ & $206(61)$ & \\
\hline Diagnosis at stem cell transplantation $(n=424)$ & & & 0.5 \\
\hline Myelodysplastic syndrome & $12(14)$ & $64(19)$ & \\
\hline Acute myeloid leukemia & $50(59)$ & $195(57)$ & \\
\hline Secondary acute myeloid leukemia & $23(27)$ & $80(24)$ & \\
\hline Disease status at stem cell transplantation $(n=412)$ & & & 0.9 \\
\hline Complete remission & $37(45)$ & $141(43)$ & \\
\hline Not in complete remission & $39(47)$ & $155(47)$ & \\
\hline Untreated & $7(8)$ & $33(10)$ & \\
\hline Cytogenetics $(n=350)$ & & & 0.5 \\
\hline Normal & $36(53)$ & $135(48)$ & \\
\hline Abnormal & $32(47)$ & $147(52)$ & \\
\hline Stem cell source $(n=424)$ & & & 0.06 \\
\hline Bone marrow & $7(8)$ & $11(3)$ & \\
\hline Peripheral blood stem cells & $78(92)$ & $328(97)$ & \\
\hline Conditioning intensity $(n=424)$ & & & 0.5 \\
\hline Myeloablative conditioning & $51(60)$ & $188(56)$ & \\
\hline Reduced intensity conditioning & $34(40)$ & $151(44)$ & \\
\hline Antithymocyte globulin use $(n=424)$ & & & 1.0 \\
\hline No & $14(17)$ & $59(17)$ & \\
\hline Yes & $71(83)$ & $280(83)$ & \\
\hline HLA-A mismatch $(n=424)$ & & & 1.0 \\
\hline No & $61(72)$ & $244(72)$ & \\
\hline Yes & $24(28)$ & $95(28)$ & \\
\hline HLA-B mismatch $(n=424)$ & & & 0.2 \\
\hline No & $71(84)$ & $301(89)$ & \\
\hline Yes & $14(16)$ & $38(11)$ & \\
\hline HLA-C mismatch $(n=424)$ & & & 0.2 \\
\hline No & $61(72)$ & $217(64)$ & \\
\hline Yes & $24(28)$ & $122(36)$ & \\
\hline HLA-DRB1 mismatch $(n=424)$ & & & 0.3 \\
\hline No & $73(86)$ & $305(90)$ & \\
\hline Yes & $12(14)$ & $34(10)$ & \\
\hline HLA-DQB1 mismatch $(n=424)$ & & & 0.6 \\
\hline No & $75(88)$ & $289(85)$ & \\
\hline Yes & $10(12)$ & $50(15)$ & \\
\hline
\end{tabular}


Table 1 (continued)

\begin{tabular}{lccc}
\hline Characteristics & PIRCHE $=0$ & PIRCHE $>0$ & $p$ value \\
\hline HLA-C mismatch $(n=424)$ & & & $<0.001$ \\
$\quad$ No & $61(72)$ & $217(64)$ & \\
$\quad$ Yes, antigen mismatch & $9(11)$ & $103(30)$ & \\
$\quad$ Yes, allele mismatch & $15(17)$ & $19(6)$ & $<0.001$ \\
HLA-C mismatch C*03:03 vs. 03:04 $(n=424)$ & $72(85)$ & $328(97)$ & \\
$\quad$ No & $13(15)$ & $11(3)$ & 0.4 \\
$\quad$ Yes & $53(62)$ & $229(68)$ & \\
TBI conditioning $(n=424)$ & $32(37)$ & $110(32)$ & \\
$\quad$ No & & \\
Yes &
\end{tabular}

Data are presented as $n(\%)$ or median (range).

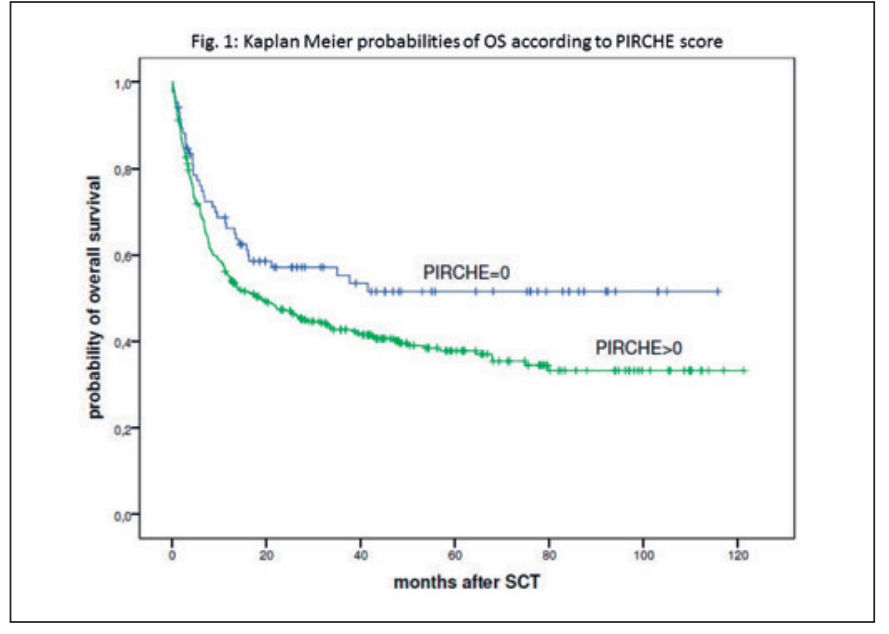

Fig. 1. Kaplan-Meier probabilities of OS according to PIRCHE score. The cohort of 424 patients transplanted from a 9/10 MMUD was stratified according the PIRCHE score $=0(n=85)$ or $>0(n=$ 339). For Kaplan-Meier estimates, see text.

\section{Graft-Versus-Host Disease}

Finally, we analyzed the impact of PIRCHE score on acute and chronic GVHD. Cumulative incidence of acute GVHD grade 2-4 at 6 months was not different for 9/10 MUD with PIRCHE score 0 compared to PIRCHE score $>0$ ( 23 vs. $30 \%, p=0.2$; Fig. 3 ). Cumulative incidence of chronic GVHD at 2 years was lower for 9/10 MUD with PIRCHE score 0 compared to PIRCHE score $>0$ (31 vs. $49 \%, p=0.04$; Fig. 4 ).

\section{Discussion}

Single mismatched unrelated donors are one of the most frequently used alternative graft sources for allogeneic stem cell transplantation. However, there is no established standardized system for selection of HLA-mismatched donors. Although associations between specific

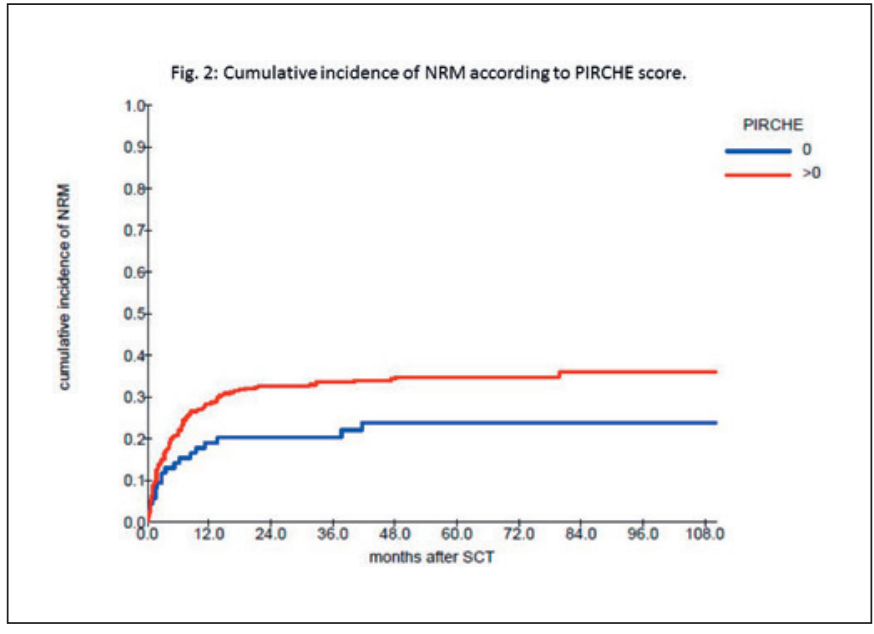

Fig. 2. Cumulative incidence of NRM according to PIRCHE score. The cohort of 424 patients transplanted from a 9/10 MMUD was stratified according the PIRCHE score $=0(n=85)$ or $>0(n=339)$. For Kaplan-Meier estimates, see text.

HLA disparities and outcome have been identified in large cohort studies [18-20], these findings are limited to the specific HLA loci and the particular mismatch under investigation. More so, the HLA heterogeneity in ethnically mixed populations like Europeans and the Americans, poses a major barrier to such epidemiologically based strategies [21].

Our study is based on high-resolution typing for HLA$\mathrm{A},-\mathrm{B},-\mathrm{C},-\mathrm{DRB} 1$, and -DQB1 because this is general practice in the participating centers. Typing for HLA-DPB1 was not routinely performed. The differential impact of single HLA disparities in locus A, B, C, and DRB1 has been and is still an issue of controversy $[3,4,6]$. In our study, HLA-A disparity was associated with higher risk of NRM compared to other HLA mismatches (Table 2a, b). Transplants with disparities in HLA-DQB1 were associated with better OS than other mismatches, also confirming previous reports $[3,4,6]$. 
Table 2. Multivariate Cox regression analysis of patients with $9 / 10$ MUD $(n=424)$

\begin{tabular}{|c|c|c|}
\hline Parameter & HR (95\% CI) & $p$ value \\
\hline \multicolumn{3}{|l|}{ a Overall survival } \\
\hline \multicolumn{3}{|l|}{ PIRCHE score } \\
\hline PIRCHE score $=0$ & 1 & \\
\hline PIRCHE score $>0$ & $1.5(1.0-2.1)$ & 0.03 \\
\hline \multicolumn{3}{|l|}{ Patient CMV status } \\
\hline Negative & 1 & \\
\hline Positive & $1.4(1.1-1.9)$ & 0.01 \\
\hline \multicolumn{3}{|c|}{ Remission status at stem cell transplantation } \\
\hline Complete remission & 1 & \\
\hline Not in complete remission & $1.7(1.3-2.2)$ & $<0.001$ \\
\hline \multicolumn{3}{|l|}{ HLA mismatch } \\
\hline Non-HLA-DQB1 mismatch & 1 & \\
\hline HLA-DQB1 mismatch & $0.5(0.3-0.8)$ & 0.002 \\
\hline \multicolumn{3}{|l|}{ b Non-relapse mortality } \\
\hline \multicolumn{3}{|l|}{ PIRCHE score } \\
\hline PIRCHE score $=0$ & 1 & \\
\hline PIRCHE score $>0$ & $1.7(1.0-2.9)$ & 0.03 \\
\hline \multicolumn{3}{|l|}{ Patient CMV status } \\
\hline Negative & 1 & \\
\hline Positive & $1.5(1.1-1.5)$ & 0.02 \\
\hline \multicolumn{3}{|c|}{ Remission status at stem cell transplantation } \\
\hline Complete remission & 1 & \\
\hline Not in complete remission & $1.5(1.2-1.9)$ & $<0.001$ \\
\hline \multicolumn{3}{|l|}{ HLA mismatch } \\
\hline Non-HLA-A mismatch & 1 & \\
\hline HLA-A mismatch & $1.5(1.0-2.2)$ & 0.03 \\
\hline \multicolumn{3}{|l|}{ HLA mismatch } \\
\hline Non-HLA-DQB1 mismatch & 1 & \\
\hline HLA-DQB1 mismatch & $0.4(0.2-0.8)$ & 0.01 \\
\hline
\end{tabular}

Our results show that the PIRCHE algorithm enables detection of permissive mismatches in 9/10 MUD HSCT. Such permissive mismatches may include already known alleles such as HLA-C*03:03 vs. 03:04 as well as others that have not yet been specifically studied. In our cohort, detection of any PIRCHE (score $>0$ ) was associated with poorer outcome in terms of NRM and OS.

The current PIRCHE model considers all peptides within defined binding values as relevant and scores them equally, irrespective of their positioning in the peptide binding groove of the HLA molecule and polymorphisms that may influence T-cell recognition [21]. A higher PIRCHE score may therefore not necessarily reflect a proportional increase in alloreactivity. This is a possible reason why increasing PIRCHE numbers as continuous variable were not associated with survival outcome (data not shown).

Detection of PIRCHE was associated with a higher cumulative incidence of chronic GVHD but not acute GVHD. This finding is in line with the notion that indirect $\mathrm{T}$-cell recognition, which is believed to involve the naïve rather than memory $\mathrm{T}$ cells, may elicit slow rather than early acute alloreactivity [22].

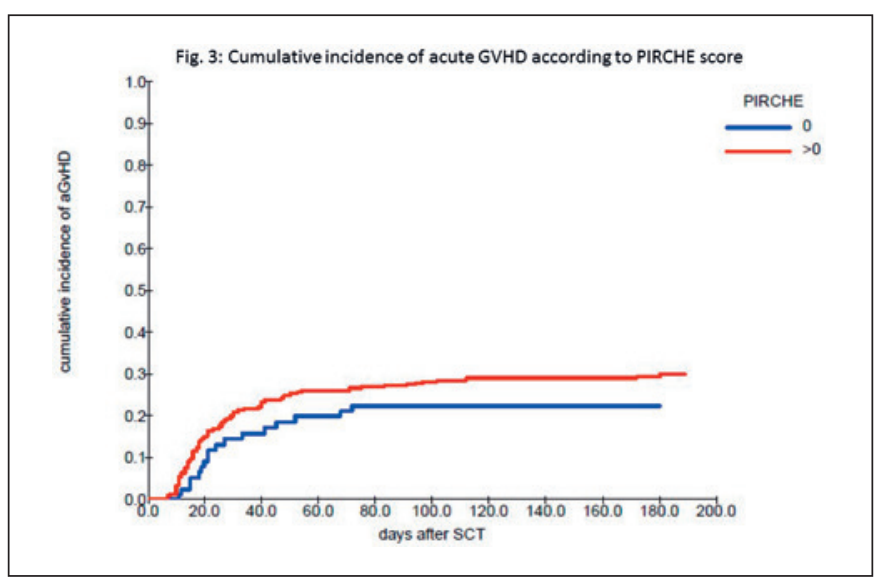

Fig. 3. Cumulative incidence of acute GVHD according to PIRCHE score. The cohort of 424 patients transplanted from a 9/10 MMUD was stratified according the PIRCHE score $=0(n=85)$ or $>0(n=$ 339). For Kaplan-Meier estimates, see text.

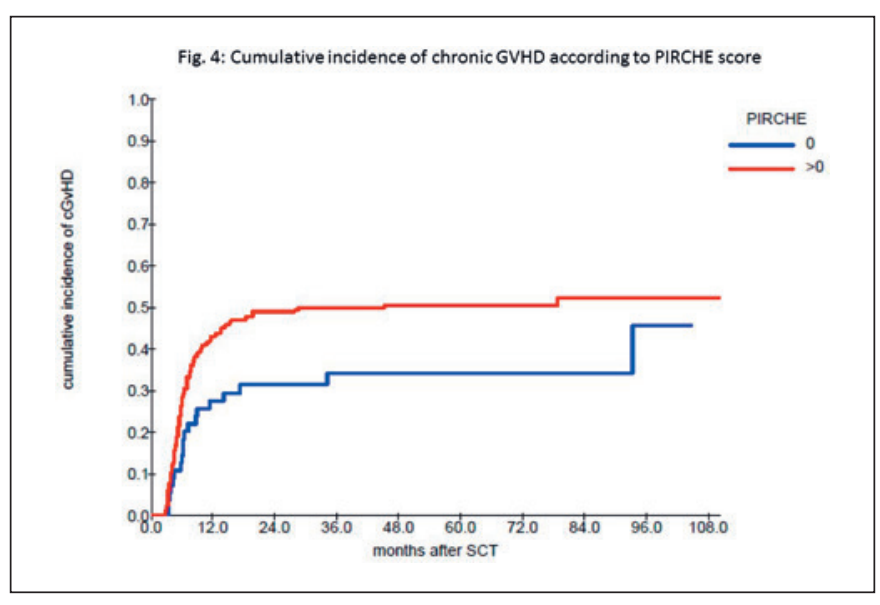

Fig. 4. Cumulative incidence of chronic GVHD according to PIRCHE score. The cohort of 424 patients transplanted from a 9/10 MMUD was stratified according the PIRCHE score $=0(n=$ $85)$ or $>0(n=339)$. For Kaplan-Meier estimates, see text.

PIRCHE is currently the only existing model that predictsindirectrecognition of HLA mismatches. The PIRCHE model has recently been reported to refine the TCE model for selection of permissible HLA-DPB1 epitopes [23] indicating that models predicting direct and indirect recognition of HLA mismatches may be complementary.

To the best of our knowledge, for the first time, we report a clinically relevant impact of this computer-based prediction of indirect T-cell recognition of HLA mismatches on survival outcome after allogeneic HSCT.

Our study is limited by its retrospective character and lack of DPB1 typing. Our results nonetheless indicate that PIRCHE may allow selection of permissible HLA mismatches that would enable improved transplant outcome in terms of reduced NRM and better OS. These results, 
however, need confirmation in another large retrospective or prospective study before PIRCHE can become a new instrument for selection of HLA-mismatched donors.

\section{Acknowledgements}

The authors wish to thank all the center data managers for excellent support in data acquisition and management.

\section{Statement of Ethics}

All procedures performed in studies involving human participants were in accordance with the ethical standards of the institutional and/or national research committee and with the $1964 \mathrm{Hel}-$ sinki Declaration and its later amendments or comparable ethical standards. Written informed consent was available from all patients.

\section{Disclosure Statement}

This work was supported by a research grant from PIRCHE AG to the University Medical Center Hamburg. All authors do not have any conflicting interest with PIRCHE AG or the PIRCHE algorithm and declare no further conflicts of interest.

\section{Funding Sources}

This study was supported by a research grant from PIRCHE AG to the University Medical Center Hamburg.

\section{Author Contributions}

F.A., W.B., and M.B. designed the study. T.Z. and M.C. performed statistics. F.A., M.B., M.S., E.-M.W., C.S., M.G., N.K., and W.B. collected and interpreted data. F.A. wrote the manuscript, all others revised the manuscript.

\section{References}

1 Gragert L, Eapen M, Williams E, Freeman J, Spellman S, Baitty R, et al. HLA match likelihoods for hematopoietic stem-cell grafts in the U.S. registry. N Engl J Med. 2014 Jul; 371(4):339-48.

2 Flomenberg N, Baxter-Lowe LA, Confer D, Fernandez-Vina M, Filipovich A, Horowitz $\mathrm{M}$, et al. Impact of HLA class I and class II high-resolution matching on outcomes of unrelated donor bone marrow transplantation: HLA-C mismatching is associated with a strong adverse effect on transplantation outcome. Blood. 2004 Oct;104(7):1923-30.

3 Lee SJ, Klein J, Haagenson M, Baxter-Lowe LA, Confer DL, Eapen M, et al. High-resolution donor-recipient HLA matching contributes to the success of unrelated donor marrow transplantation. Blood. 2007 Dec;110(13): 4576-83.

4 Woolfrey A, Klein JP, Haagenson M, Spellman S, Petersdorf E, Oudshoorn M, et al. HLA-C antigen mismatch is associated with worse outcome in unrelated donor peripheral blood stem cell transplantation. Biol Blood Marrow Transplant. 2011 Jun;17(6):885-92.

5 Horan J, Wang T, Haagenson M, Spellman SR, Dehn J, Eapen M, et al. Evaluation of HLA matching in unrelated hematopoietic stem cell transplantation for nonmalignant disorders. Blood. 2012 Oct;120(14):2918-24.

6 Fürst D, Müller C, Vucinic V, Bunjes D, Herr W, Gramatzki M, et al. High-resolution HLA matching in hematopoietic stem cell transplantation: a retrospective collaborative analysis [Erratum in: Blood. 2014 Mar 13;123] [11]. Blood. 2013 Oct;122(18):3220-9.

7 Fleischhauer K, Shaw BE, Gooley T, Malkki $\mathrm{M}$, Bardy P, Bignon JD, et al.; International Histocompatibility Working Group in Hematopoietic Cell Transplantation. Effect of Tcell-epitope matching at HLA-DPB1 in recipients of unrelated-donor haemopoietic-cell transplantation: a retrospective study [Erratum in: Lancet Oncol. 2012 Apr;13] [4] [:e1345]. Lancet Oncol. 2012 Apr;13(4):366-74.
8 Fernandez-Viña MA, Wang T, Lee SJ, Haagenson M, Aljurf M, Askar M, et al. Identification of a permissible HLA mismatch in hematopoietic stem cell transplantation. Blood. 2014 Feb;123(8):1270-8.

9 Zino E, Frumento G, Marktel S, Sormani MP, Ficara F, Di Terlizzi S, et al. A T-cell epitope encoded by a subset of HLA-DPB1 alleles determines nonpermissive mismatches for hematologic stem cell transplantation. Blood. 2004 Feb;103(4):1417-24.

10 Crocchiolo R, Zino E, Vago L, Oneto R, Bruno B, Pollichieni S, et al.; Gruppo Italiano Trapianto di Midollo Osseo, Cellule Staminale Ematopoietiche (CSE) e Terapia Cellulare; Italian Bone Marrow Donor Registry. Nonpermissive HLA-DPB1 disparity is a significant independent risk factor for mortality after unrelated hematopoietic stem cell transplantation. Blood. 2009 Aug; 114(7):1437-44.

11 Pidala J, Lee SJ, Ahn KW, Spellman S, Wang $\mathrm{HL}$, Aljurf M, et al. Nonpermissive HLADPB1 mismatch increases mortality after myeloablative unrelated allogeneic hematopoietic cell transplantation. Blood. 2014 Oct; 124(16):2596-606.

12 Jöris MM, van Rood JJ, Roelen DL, Oudshoorn M, Claas FH. A proposed algorithm predictive for cytotoxic T cell alloreactivity. J Immunol. 2012 Feb;188(4):1868-73.

13 Spellman S, Klein J, Haagenson M, Askar M, Baxter-Lowe LA, He J, et al. Scoring HLA Class I Mismatches by HistoCheck Does Not Predict Clinical Outcome in Unrelated Hematopoietic Stem Cell Transplantation. Biol Blood Marrow Transplant. 2012 May;18(5): 739-46.

14 Otten HG, Calis JJ, Keşmir C, van Zuilen AD, Spierings E. Predicted indirectly recognizable HLA epitopes presented by HLA-DR correlate with the de novo development of donorspecific HLA IgG antibodies after kidney transplantation. Hum Immunol. 2013 Mar; 74(3):290-6.
15 Thus KA, Te Boome L, Kuball J, Spierings E. Indirectly Recognized HLA-C Mismatches and Their Potential Role in Transplant Outcome. Front Immunol. 2014 May;5:210.

16 Przepiorka D, Weisdorf D, Martin P, Klingemann HG, Beatty P, Hows J, et al. 1994 Consensus Conference on Acute GVHD Grading. Bone Marrow Transplant. 1995 Jun;15(6):825-8.

17 Shulman HM, Sullivan KM, Weiden PL, McDonald GB, Striker GE, Sale GE, et al. Chronic graft-versus-host syndrome in man. A longterm clinicopathologic study of 20 Seattle patients. Am J Med. 1980 Aug;69(2):204-17.

18 Kawase T, Morishima Y, Matsuo K, Kashiwase K, Inoko H, Saji H, et al.; Japan Marrow Donor Program. High-risk HLA allele mismatch combinations responsible for severe acute graft-versus-host disease and implication for its molecular mechanism. Blood. 2007 Oct;110(7):2235-41.

19 Fernandez-Viña MA, Wang T, Lee SJ, Haagenson M, Aljurf M, Askar M, et al. Identification of a permissible HLA mismatch in hematopoietic stem cell transplantation. Blood. 2014 Feb;123(8):1270-8.

20 Baxter-Lowe LA, Maiers M, Spellman SR, Haagenson MD, Wang T, Fernandez-Vina M, et al. HLA-A Disparities Illustrate Challenges for Ranking the Impact of HLA Mismatches on Bone Marrow Transplant Outcomes in the United States. Biol Blood Marrow Transplant. 2009 Aug;15(8):971-81.

21 Geneugelijk K, Thus KA, Spierings E. Predicting Alloreactivity in Transplantation. J Immunol Res. 2014;2014:159479.

22 Bolton EM, Bradley JA, Pettigrew GJ. Indirect allorecognition: not simple but effective. Transplantation. 2008 Mar;85(5):667-9.

23 Thus KA, Ruizendaal MT, de Hoop TA, Borst E, van Deutekom HW, Te Boome L, et al. Refinement of the definition of permissible HLA-DPB1 mismatches with predicted indirectly recognizable HLA-DPB1 epitopes. Biol Blood Marrow Transplant. 2014 Nov;20(11): 1705-10. 